\title{
Aspartame: effects and awareness
}

\begin{abstract}
Aspartame is very popular artificial sweetener with very low calorific value. Since last few decades use of aspartame has been drastically enhanced among the population worldwide. Not only the diabetic persons but also diet conscious young and teen-agers are also consuming aspartame without any concern or much knowledge. Consumers are using the aspartame irrespective of their clinical conditions and age. Sugar free diet products are very much popular among children and teenagers. It has been also noticed that, aspartame issued under commercial trade without any warning or specific intake limit on label. Presently aspartame consumed widely by the population via cold drinks, diet soda, low calorie sweet products, sugar free sweet products and medications. Although, many research studies indicate clearly about the associated side effects of aspartame consumption. So, in the light of available scientific research, the use of this synthetic sweetener is questionable and controversial. Purpose of this review is to spread the awareness about the possible adverse after effects of unconscious aspartame consumption. Present review is an interactive and comprehensive presentation of facts and information related to aspartame for the awareness of researchers and mass population.
\end{abstract}

Volume 3 Issue 2 - 2017

\author{
Tabassum Zafar, Qayoom Naik AB,Vinoy K \\ Shrivastava \\ Department of Biosciences, Barkatullah University, India
}

Correspondence: Tabassum Zafar, Department of Biosciences, Laboratory of Endocrinology, Barkatullah University, Bhopal 462026, India, Fax 07552517003

Email tztabassumzafar@gmail.com

Received: January 25, 2017 | Published: March 30, 2017

Keywords: aspartame; artificial sweeteners; low calorie sweeteners; non-sugar sweeteners

\section{Introduction}

Aspartame (E951) is a synthetic, dipeptide, intense sweetener, which is almost 180-200 times sweeter than sucrose, with a respective low calorific value. Aspartame is widely used in more than 6000 products worldwide with a huge commercial outcome under many brand names. ${ }^{1}$ Aspartame is very much popular owing to its reduced costs, low caloric intake, attractive advertisements and assurance to contribute in weight management. The popularity of aspartame among consumers lies down within the problems associated with sucrose consumption. ${ }^{2}$ In diabetic individuals difficulty in regulating their blood sugar levels restrict the consumption of normal sugar. This is due to the fact that diabetics do not have sufficient levels of insulin, a hormone that controls sugar uptake in the bloodstream. Aspartame helps in limiting the sucrose intake in the form of substituting sugar and releases very low amount of energy respectively. It is metabolized more slowly than sucrose, allowing blood sugar levels to remain more stable over time. Individuals with reactive hypoglycemia produce an excess of insulin after quickly absorbing glucose into the bloodstream. ${ }^{3}$ This causes their blood glucose levels to fall below the amount needed for physiological function. Like diabetic, high glycemic food avoidance often force to choose artificial sweeteners as an alternative. Sucrose promotes tooth decay due to the fact that bacteria that naturally occur in the human oral cavity are able to efficiently use sucrose as a food source, releasing wastes that degrade enamel. Unlike sucrose, the micro flora present in the dental plaque does not utilize aspartame. Due to this property use of aspartame is recommended in the form of prescribe sugar free medicines whenever possible. ${ }^{4,5}$ For these reasons, aspartame increasingly introduced into commonly consumed foods such as diet sodas, cereals and sugar-free desserts, yoghurt, chewing gums, syrups, mouth fresheners, candies, health drinks, nutritional supplements and are being recommended for weight loss and for individuals suffering from glucose intolerance and type 2 diabetes mellitus.

\section{Chemical information related to aspartame}

Discovery: In 1965 a chemist named James Schlatter working in the G. D. Searle research laboratories accidently has been discovered aspartame. During one intermediate reaction of gastrin inhibitor preparation, accidentally some of the solution spilled on his hand. Irrespective of all safety measures he licked his finger to pick up the piece of paper and came to know about the intense sweet taste of chemical. ${ }^{7}$ In 1970 Cloninger and Baldwin published report in Science to propose its use as an artificial sweetener. ${ }^{8}$

\section{Synthesis}

However synthesis of aspartame is slightly complicated a direct Incubation of L- aspartic acid and methyl ester of phenyl- alanine along with some microorganisms also yield aspartame at commercial level. Chemical synthesis of aspartame involves two major chemical processes named Z- and F- processes. The Z-process mainly involves the dehydration of the benzyloxycarbonyl-L-aspartic acid with acetic anhydride. The anhydride is then coupled with the methyl ester of L- phenylalanine in toluene to give a mixture of benzyloxy carbonyl $\alpha$-and $\beta$ aspartames. The protecting groups are removed by hydrogenolysis. After crystallization mixture of $\alpha$-and $\beta$ aspartame isomers yield aspartame. ${ }^{9}$ The F-process involves the protection of the amino group of aspartic acid with a formyl group followed by natural dehydration to form anhydride. The anhydride is then coupled either with L-phynylalanine or its methyl ester and the formyl group removed by acid hydrolysis. ${ }^{10}$ The resultant mixture of $\alpha$ and $\beta$ aspartame treated with aqueous methanol treatment, crystallization and neutralization finally provides commercial aspartame.

\section{Chemical and physical properties}

Aspartame is composed of two amino acid L-aspartic acid and L-phenylalanine. It is a white crystalline, odorless intensively sweet powder has the molecular formula (Figure 1) $\mathrm{C}_{14} \mathrm{H}_{18} \mathrm{~N}_{2} \mathrm{O}_{5}$ along with the molar mass $294.31 \mathrm{~g} \mathrm{~mol}^{-1}$. The density of Aspartame is $1.347 \mathrm{~g} /$ 
$\mathrm{cm}^{3}$ with a high melting point, between $246-247^{\circ} \mathrm{C}$. Under strong alkaline and acidic conditions aspartame hydrolyzed. In aqueous solution the relationship between $\mathrm{pH}$ and stability of aspartame is a bell-shaped curve with the maximum stability at $\mathrm{pH} 4.3$. The solubility of aspartame changes in respect of changes in $\mathrm{pH}$ and temperature. Accept water aspartame is also slightly soluble in alcohol. Aspartame is more soluble in higher temperature acidic solutions. Solubility of aspartame in water is about $0.03 \mathrm{gm} / \mathrm{ml}$ on acidic $\mathrm{pH} 3$ at room temp. Being a dipeptide aspartame has some limitations. It is supposed to loss its integrity during heating, therefore cannot be used in baking, cooking or prolonged storage in liquids. ${ }^{11,12}$

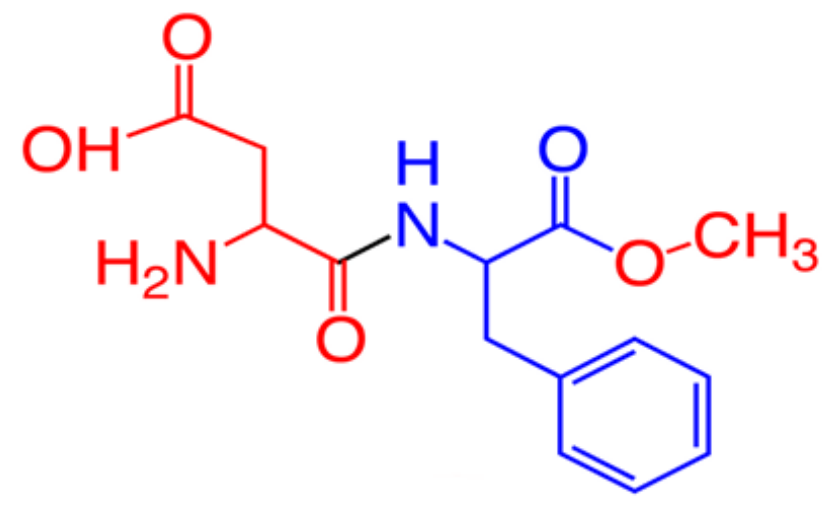

Figure I Chemical structure of aspartame.

\section{Biochemistry of aspartame}

Hydrolysis: Ones ingested soon aspartame undergoes to hydrolysis in intestinal lumen and converts into three hydrolytic products named as phenylalanine $(50 \%)$, aspartic acid $(40 \%)$ and methanol $(10 \%) .{ }^{13}$

Metabolism: Aspartame widely used to sweeten a variety of low and reduced calorie diet foods and beverages. Once ingested during metabolism, aspartame breaks down in intestinal lumen. Apart from it's constituent amino acids aspartic acid and phenylalanine and methanol it further breakdown to form formaldehyde, formic acid, diketopiperazine, which further metabolized in vivo. ${ }^{14,15}$ Production of essential amino acid phenylalanine is a health hazard to those born with phenylketonuria (PKU) a rare inherited disease. However methanol production is not very high during aspartame metabolism but still it contributes to the toxicities. ${ }^{16}$

\section{Mode of action possibly responsible for adverse effect}

A product of aspartame metabolism Phenylalanine plays an important role in neurotransmitter regulation. ${ }^{17}$ Aspartic acid has an important role as an excitatory neurotransmitter in the central nervous system along with glutamate. Glutamate, asparagine and glutamine are formed from their precursor, aspartic acid. Methanol converted in the body to formate, which can either be excreted or can give rise to formaldehyde and diketopiperazine (a carcinogen) and a number of other highly toxic derivatives. Mitochondria damage by aspartame, promotes cell apoptosis leading to production of GABA. After that cell wall disruption occurs and cells become more permeable. This phenomenon creates damage of cellular endothelium of the capillaries. It gives rise to oxidative stress resulting in neurodegeneration. Direct and indirect neurological side effects related to consumption of aspartame also adversely affect the compromised learning and emotional functioning. Aspartame metabolism alters the concentrations of norepinephrine, epinephrine and dopamine. Lack of sleep, seizures, depression, and headaches are the possible side effects of alteration in regional brain concentrations of catecholamines. ${ }^{13}$

\section{Historic milieu of aspartame controversy}

The safety assessment procedure in the case of aspartame and other synthetic food additives undergoes various monitoring procedures. Safety of aspartame has been evaluated by various regulatory agencies. Food and drug administration (FDA) and other regulatory authorities consider aspartame as a safe flavor enhancer and sweetening agent but status of aspartame is still controversial, due to availability of ample amount of literature about negative health impact and adverse effect of aspartame consumption. ${ }^{17,18}$ The very first controvery related to aspartame use raised after almost two and a half decade after the aspartame discovery, when in 1996, Ralph G. Walton, a psychologist at Northeastern Ohio Universities College of Medicine, self- published analysis of aspartame and concluded at very first time research that industry-funded studies found no safety concerns while 84 of 92 independent studies (in the form of nonindustry funded studies, letters to the editors, case reports, review, articles or book chapters) did identify safety concerns. ${ }^{19}$ This issue was become popular after highlighting by a television show 60 minutes and has been extensively discussed. In a rebuttal to Walton's statements, the aspartame Information Service (a service provided by Ajinomoto, a primary producer and supplier of aspartame) expresses its disagreement. ${ }^{20}$ In 2005 a John Briffa mentioned that almost $100 \%$ of industry funded (either whole or in part) studies have conclusion that aspartame is safe, while $92 \%$ of independently funded studies have found that aspartame has the potential for adverse effects. ${ }^{21}$ This information was quite unexpected and surprising for the society. Aspartame has been used in food for more than three decades. Its safety has been evaluated by various regulatory agencies by time to time. He suggested a strong need of revaluation of safety assessments to draw new updated decisions over time. ${ }^{22}$ Since the first adverse effect of aspartame revealed through experimentation aspartame remain a chemical of interest for researchers. Noteworthy assessment of the safety status of aspartame as a non-nutritive sweetener was a critical study performed by an independent panel of recognized experts in the headship of Dr. William Waddell. The panel selection was based on achieving international representation from various areas of toxicology relevant to aspartame including toxicokinetics, metabolism, pathology, food toxicology, biostatistics, epidemiology, and general toxicology. Scientific literature on the absorption, metabolism, toxicology and epidemiological studies and worldwide current consumption levels on aspartame have been investigated by the panel..$^{23,24}$

\section{Possible associated health concerns}

The number of people suffering from diabetes, obesity, hypertension, and heart disease etc. are increasing every year. Increasing amounts of sugars in food, sweets, soft drinks etc. have raised some concern about their health effects. However nowadays artificial sweetener are receiving wide attention. But it is very important to monitor their safety issue. Aspartame was found to have association with the progression of many clinical disorders including hepatotoxicity, nephrotoxicity, neurotransmitter imbalance, and cognitive abnormalities. It was observed that males were more susceptible than females in many cases. ${ }^{25-28}$ High level of the naturally occurring essential amino acid phenylalanine is a health hazard to 
those born with phenylketonuria (PKU) a rare inherited disease. So the patients of phenylketonuria should not consume aspartame. ${ }^{28}$ Aspartame could be a leading cause for behavioral alterations including Impulsive behavior, lack of patience, decrease in locomotor activity and neuromuscular coordination. ${ }^{29}$ Aspartame consumption during gestation could be prejudicial to the fetus. Reduction in mean placental and maternal-fetal weights, in umbilical cord length and kariometric parameters in fetal hepatocyte nuclei majority of kariometric parameters of the hepatocytes were also well documented after aspartame treatment in rats. ${ }^{6}$ In utero exposure of aspartame may affect spatial cognition and glucose homeostasis in mice, particularly in males. ${ }^{25} \mathrm{An}$ increment in the body weight, transitory increases in the blood pressure and in plasma values of glucose and triglycerides alongside a transitory reduction in plasma urea was also reported after aspartame consumption. ${ }^{8}$ Alteration of Glucose homeostasis by aspartame ingestion was also well documented a decade before. ${ }^{25}$ Aspartame had the capacity to alter the normal antioxidant enzyme pool in many organs like liver and kidney. ${ }^{30}$ Even long-term consumption of aspartame could lead to oxidative stress in the erythrocytes and blood cells too. ${ }^{31}$ Aspartame treatment also was found as a leading cause of oxidative stress in immune organs such as the spleen, thymus, lymph nodes and bone marrow of folate deficient aspartame treated rats. Production of free radical production in such sensitive organs could contribute to low immunity and make the organ susceptible for infections. ${ }^{32}$ Aspartame was also found to be a potential carcinogen for some animal models. However no significant proof was available from epidemiological assessment. ${ }^{33}$ Aspartame was found to be a culprit of induction of hepatocellular carcinoma and bronchial carcinoma in male mice when it was introduced prenatally through life span via feed. ${ }^{27}$ Salivary glands are also sensitive towards aspartame exposure. Degenerative changes in the parotid salivary glands tissue architectures were reported in rodent model along with hyperchromatism, pleomorphism and abnormal mitosis in submandibular gland. ${ }^{34}$ Aspartame could also be responsible for reduction in red blood cell count, packed cell volume, hemoglobin concentration, white blood cell count platelets count and testosterone hormone followed by decrease in acetyl cholinesterase enzyme activity. ${ }^{29}$ Consecutive, oral administration of aspartame resulted in significant increase in brain interleukin-1 IL- $\beta$ (IL- $\beta$ ) and tumor necrosis factor- $\alpha$ (TNF- $\alpha$ ) production accompanied with a significant decrease in brain-derived neurotropic factor (BDNF) and serotonin levels. ${ }^{35}$ Aspartame consumption resulted in detectable amount of methanol in blood. It is supposed that metabolites of aspartame including methanol could responsible for the generation of oxidative stress in brain regions. ${ }^{36}$ Light and electron microscopic histological study revealed that oral administration of aspartame (even in small dose as $250 \mathrm{mg} / \mathrm{kg} /$ day for six weeks) could result in marked affection of the frontal cortex. ${ }^{37}$

\section{Legislations}

Under Europian and Irish legislation, all food products containing aspartame or aspartame-acesulfame salt, designated in the list of ingredients by their specific name, should be clearly labeled with the words "contains a source of phenylalanine", on the label. If aspartame (E 951) or aspartame-acesulfame salt (E 962) is designated in the list of ingredients then the label must state, "Contains aspartame (a source of phenylalanine)".38

\section{Perspective}

Although research findings in rodents have demonstrated numerous negative effects of aspartame, the status of aspartame is still debatable. Apart from all the controversy, aspartame is widely available in market for unlimited usage without any print warning of limited intake. Two prominent reasons behind the sell and purchase game are, lack of awareness about the chemistry behind the artificial sweetness and poor correlation capacity of society individuals between track of consumption and associated health issues. All the experimental research data available in the form literature still seems insufficient to prove the total safety of aspartame usage. Many funded research studies states the story of safety while many independent research experiments correlates many adverse effect with aspartame consumption. Further research experiments are required to recapitulate the facts available about aspartame in a bias free manner. Now it's time to end the controversy by appropriate experiments required for assessment of the impact of aspartame and its metabolites on in-vivo environment. Contribution of aspartame in progression of different clinical disorder should also be investigated. Females should also avoid consumption of aspartame especially during pregnancy, gestation and lactation. Aspartame is also very popular in other classes of society due to its low calorie content. Aspartame is incorporated as a substitute of table sugar to facilitate weight loss. ${ }^{39}$ People should avoid the consumption of diet products, which contains aspartame as sweetening agent. Instead of consuming such sweet product they should prefer the diet substances, which are neutral in taste, and consumes natural low sugar content. Aspartame consumption by infants and children in the form of commercially available chewing gums, toffee, sugar free sweet products, health supplements powders and diet cold drinks should strongly discourage from parents cautiously. Even sometimes, very young babies and infants easily gets in contact with aspartame in form of candy, toffee, low calorie snacks, biscuits, diet coke and mouth fresheners. Continuous exposure of aspartame in such an early life could lead to severe metabolic disturbances. ${ }^{40}$ There are many evidences available in the form of literature, which correlates between aspartame usage and health disturbances. Although aspartame is considered safe for adult use it is still not recommended for children. Although aspartame is a sweet boon for those who are diabetic and not capable to consume routine sugar due to their health concerns related to sugar intake still strict monitoring is very much required. Authors recommend the consumption of aspartame should be monitored by diabetic consumers too because, it is not necessary to use artificial sweetener in each meal. Instead it should be treated as a perception of taste. Everyone should remind that no synthetic molecule is adaptable to human body like the natural, herbal, non-toxic substance. To fulfill the existing research gaps new clinical studies are advisable. The use of aspartame is fine within the predetermined limits. Aspartame is just a molecule, which mimics the sweet taste for the taste buds of tongue; it's not a natural form of sugar. It couldn't be beneficial and safe, when it is consumed at uncontrolled manner.

\section{Conclusion}

Lastly, the authors suggest a bias free comprehensive experiment for the safety assessment of aspartame over time on different set of populations with different clinical conditions. Authors strongly discourage the use of aspartame as a sustainable source of sweetness in routine life. It is an old saying which states excess of anything is bad. Now it's time to control human greediness to excessively explore aspartame.

\section{Acknowledgements}

Authors would like to acknowledge DBT-Builder program, Department of Biotechnology (DBT), New Delhi, India for providing financial assistance. 


\section{Conflict of interest}

The author declares no conflict of interest.

\section{References}

1. Prioritization: Chemicals for Consultation by the Carcinogen Identification Committee" (Press release). California EPA Office of Environmental Health Hazard Assessment. 2009.

2. Tandel KR. Sugar substitutes: Health controversy over perceived benefits. J Pharmacol Pharmacother. 2011;2(4):236-243.

3. Bellisle F, Drewnowski A. Intense sweeteners, energy intake and the control of body weight. Eur J Clin Nutr. 2007;61:691-700.

4. Mackie IC. Children's dental health and medicines that contain sugar. BMJ. 1995;15:141-142.

5. Bentley EM, Mackie IC. A qualitative investigation into general practitioners' views on prescribing sugar free medicines for children prior to a dental health education campaign. Health Educ Res. $1993 ; 8: 519-524$

6. Portela GS, Azoubel R, Batigalia F. Effects of Aspartame on MaternalFetal and Placental Weights, Length of Umbilical Cord and Fetal Liver:A Kariometric Experimental Study. Int J Morphol. 2007;25:549 554.

7. Mazur RH. Discovery of aspartame. In Aspartame: Physiology and Biochemistry. USA: Marcel Dekker; 1989. p. 3-9.

8. Cloninger MR, Baldwin RE. Aspartylphenylalanine methyl ester: A low-calorie sweetener. Science. 1970;170(3539):81-82.

9. Ager DJ, Pantaleone DP, Henderson SA, et al. Commercial, Synthetic Nonnutritive Sweeteners. Angew Chem Int Edit. 1998;37:1802-1817.

10. Hill JB, Gelman Y, Dryden HL, Erickson R, Hsu K, et al. One-pot process for the preparation of $\alpha-\mathrm{L}$-aspartyl-L-phenylalanine methyl ester hydrochloride. Justia Patents US Patent. 1991:5053532.

11. https:// pubchem.ncbi.nlm.nih.gov/compound/aspartame

12. Mazur RH, Ripper A. Peptide-based sweeteners. UK: Applied Science Publishers; 1979.

13. Humphries P, Pretorius E, Naude H. Direct and indirect cellular effects of aspartame on the brain. European Journal of Clinical Nutrition. 2008;62:451-462.

14. Trocho C, Pardo R, Rafecas I, et al. Formaldehyde derived from dietary aspartame binds to tissue components in vivo. Life Sci. 1998;63(5):337349.

15. George V, Arora S, Wadhwa BK, et al. Analysis of multiple sweeteners and their degradation products in lassi by HPLC and HPTLC plates. $J$ Food Sci Technol. 2010;47(4):408-413.

16. Heber D. Vegetables, fruits and phytoestrogens in the prevention of diseases. J Postgrad Med. 2004;50(2):145-149.

17. Food Additive Approval Process Followed for Aspartame. Food Additive Approval Process Followed for Aspartame GAO/HRD8746 (PDF). United States General Accounting Office. 1987.

18. Food Standards Australia New Zealand: "Aspartame”. Food standards Australia New Zealand; 2011.

19. The Lowdown on Sweet? The New York Times, February 12. 2006

20. Aspartame Information replies to the New York Times. Aspartame Information Service.
21. Briffa J. Aspartame and its effects on health -Letter to editor. BMJ. 2005;330(7486):309-310.

22. Cockburn A. Rumsfeld: His Rise, Fall, and Catastrophic Legacy. USA: Scribner; 2007. 257 p.

23. Magnuson BA, Burdock GA, Doull J, et al. Aspartame: a safety evaluation based on current use levels, regulations and toxicological and epidemiological studies. Crit Rev Toxicol. 2007;37(8):629-727.

24. Abdo KM, Camargo CA, Davis D, et al. Letter to U.S. FDA commissioner. Questions about the safety of the artificial sweetener aspartame. Int J Occup Environ Med. 2007;13:449-450.

25. Collison KS, Makhoul NJ, Zaidi MZ, et al. Interactive effects of neonatal exposure to monosodium glutamate and aspartame on glucose homeostasis. Nutr Metab (Lond). 2012;9(1):58.

26. Hiroyuki I. Incidence of brain tumors in rats fed aspartame. Toxicol Lett. 1981;7(6):433-437.

27. Soffritti M, Belpoggi F, Manservegi M, et al. Aspartame administration in feed, begning prenatally through life span induces cancer of the liver and lung in male Swiss mice. Am J Ind Med. 2010;53(12):1197-1206.

28. Morales FM, Cervantes EM, Espinoza MAI, et al. Nutritional and biochemical effects of Aspartame intake in rats under experimental diet. J Expmntl Biol \& Agri Sci. 2015;3(3):298-306.

29. Abu Tfaweel GM. Effect of monosodium glutamate and aspartame on the behavioral and biochemical parameters of albino mice. African $J$ Biotech. 2016;15(15):601-612.

30. Iman, Mourad M. Effect of aspartame on some oxidative stress parameters in liver and kidney of rats. Afr J Pharm Pharmacol. 2011;5(6):678-682.

31. Prokic MD, Paunovic MG, Matic MM, et al. Prooxidative effects of aspartame on antioxidant defense status in erythrocytes of rats. J Biosci. 2014;39(5):859-866.

32. Choudhary AK, Devi RS. Imblance of the oxidant-antioxidant status by aspartame in the organs of immune system of wistar albino mice. African J Pharm Pharmacol. 2014;8(8):220-230.

33. Gombos K, Varjas T, Orsos Z, et al. The Effect of Aspartame Administration on Oncogene and Suppressor Gene Expressions. In vivo. 2007;21(1):89-92.

34. El Sakhawy M, Saeid S. Effect of long term administration of aspartame on the parotid salivary glands of male albino rats. Intl J Advanc Res. 2014;2(3):850-857.

35. Kamel EA. Inflammation and neurochemical alterations induced by oral aspartame administration in experimental rats. Indian J Applied Res. 2015;5(10):750-753.

36. Iyyaswamy A, Rathinasamy S. Effect of chronic exposure of aspartame on oxidative stress in the brain of albino mice. J Biosci. 2012;37(4):679688.

37. Sahar M Omar. Effect of aspartame on the frontal cortex of adult male albino rats. A light and electron microscopic study. Egypt J Histol. 2009;32(2):346-357.

38. Food safety authority of Ireland. Toxicology fact series. 2015.

39. Henkel J. Sugar substitutes: Americans opt for sweetness and lite. FDA Consum. 2007;33(6):12-16.

40. Horwitz DL, Bauer Nehrling JK. Can aspartame meet our expectations. J Am Diet Association. 1983;83:142-146. 